EGU2020-20537, updated on 24 Nov 2020

https://doi.org/10.5194/egusphere-egu2020-20537

EGU General Assembly 2020

(c) Author(s) 2020. This work is distributed under

the Creative Commons Attribution 4.0 License.

\title{
Linking remotely sensed vegetation structure and soil contamination data to monitor oil spill driven degradation in the Niger Delta Mangrove
}

Matthew Brolly, Isa Kwabe, Raymond Ward, and Christopher Joyce

University of Brighton, School of Environment and Technology, United Kingdom of Great Britain and Northern Ireland (matthew.brolly@gmail.com)

In this study, soil sampling, vegetation analysis, and remotely sensed indices are used to devise a framework for monitoring impact of oil pollution on Mangrove forests. Mangroves are under threat from resource extraction and associated degradation. As a result of their inter-tidal location, Mangroves provide habitat for terrestrial and aquatic organisms and are important components of coastal ecosystems, providing a range of naturally available ecosystem services. Despite the widely accepted and documented range of ecosystem services provided by mangroves, they have nevertheless, experienced a worldwide degradation resulting from various anthropogenic activities including oil exploitation.

This research is conducted in the Niger Delta where the largest spatial extent of Mangrove forests in Africa is located, consisting of $7 \%$ of global stock. Hydrocarbon exploitation in the Niger Delta region is one of several resource extractions undertaken in the area and as a result associated environmental pollution has caused a drastic decline in the region's biodiversity and ecological resources. Of interest to this study is the effect of associated oil spills on the Mangrove forest ecosystem and their detection.

This study undertook a detailed field exercise over three seasons across the Niger Delta within close proximity to recorded oil spills; as noted in the NOSDRA (National Oil Spill Detection \& Response Agency) archive. Soil sampling and laboratory analyses were conducted to establish the level and nature of contamination and supported by complementary vegetation structure analysis evaluating Leaf Area Index (LAl) from ground (LAI2200C) and spaceborne (Landsat archive) systems. Levels of soil contamination were significant with respect to control areas regarding both presence and concentration of heavy metal pollutants ( $\mathrm{Cr}, \mathrm{Mn}, \mathrm{Fe}, \mathrm{Zn}, \mathrm{Pb}, \mathrm{Al}$ and $\mathrm{Hg}$ ). Additionally, negative structural impacts were detected on the local soil via Bulk Density reductions, known to impact soil function, as high as $0.566 \mathrm{~g} / \mathrm{cm}^{3}$ when comparing control Estuarine with high polluted locations, and Soil Organic Matter (SOM) reductions indicated by a mean percentage difference to the control of $11 \%$ for high polluted Fringing locations. These results highlight the immediate harm from spills, with degraded areas visually recorded and validated via ground measurements with mean LAl in high polluted Estuarine locations recording 1.8 higher. Linking vegetation structure in the Mangrove system with soil contamination allows the use of remote sensing to identify areas of 
degradation and subsequently to model the level and nature of contamination. The correlation between ground and spaceborne measurements of LAI (eg. $r=0.62 p<0.005$ for fringing low pollution locations), allows machine learning approaches to be used to model LAl given the presence of contaminants and to provide a framework for supporting the detection and recording of areas at risk. Success will be expanded upon through use of GEDI lidar waveforms in the near future to improve the remotely derived description of forest structure. 